\title{
Utilization of heat pipes for transfer heat from the flue gas into the heat transfer medium
}

\author{
Richard Lenhard $^{1, \mathrm{a}}$, Katarína Kaduchová ${ }^{1}, \breve{S}_{\text {tefan }}$ Papučík $^{1}$ and Jozef Jandačka ${ }^{1}$ \\ ${ }^{1}$ University of Žilina, Faculty of Mechanical Engineering, Department of Power Engineering, Univerzitna 1, \\ 01026 Žilina, Slovakia
}

\begin{abstract}
The contribution is listed possible application of heat pipes in systems for obtaining heat from flue gas of small heat sources. It is also stated in the contribution design an experimental device on which to study the impact of fill (the quantity, type of load) at various temperature parameters (temperature heating and cooling) thermal power transferred to the heat pipe. Is listed measurement methodology using heat pipes designed experimental facility, measurement results and analysis of the results obtained.
\end{abstract}

\section{Heat pipe}

Heat pipe is formed from vacuum-closed pipe and filled with a suitable working substance at a defined pressure. For purpose of the heat pipe utilization is necessary to consider several factors, which influences its proper function. The choice of the heat pipe is mainly dependent on technical applications, temperature range and compatibility of the substance with pipe material. A crucial factor is how much working substance is used like a filler heat pipe. It is necessary to over a required range of operating parameters to avoid insufficient wetting of the evaporation pipe surface. Insufficient wetting would result in a decreasing performance. Conversely too much working fluid would lead to the formation of large vapor bubbles and the shock phenomena. Figure 1 shows the description of the heat pipe function.

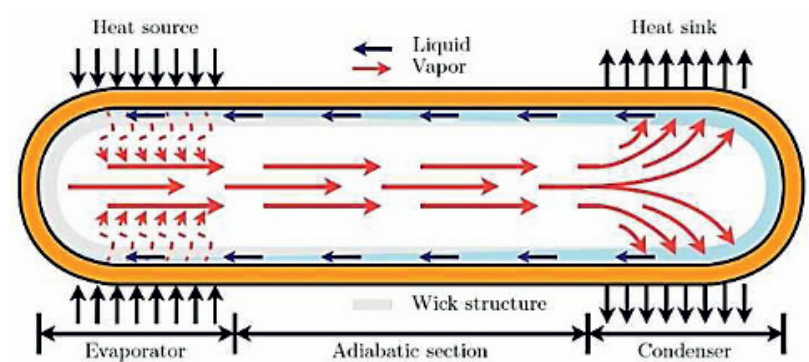

Figure 1. Description of heat-pipe (http://heatpipe.nl).

Heat pipes are used for heat transfer-heat performance, while the small temperature difference between the evaporation and condensation part is kept. By this technology can be transferred high heat performance, while device dimensions are small. The advantage of heat pipes is particularly intense heat transfer, and finally, simple design, reliability, durability and endurance. Currently, the heat pipes are applied in many branches (communication and computer technology, space technology, etc.).

\section{Experimental device}

For the purpose determination of heat pipe performance is designed an experimental device (figure 2), which can be used for measurement of the heat pipe performance with different parameters (amount of filling, heating temperature and cooling temperature).

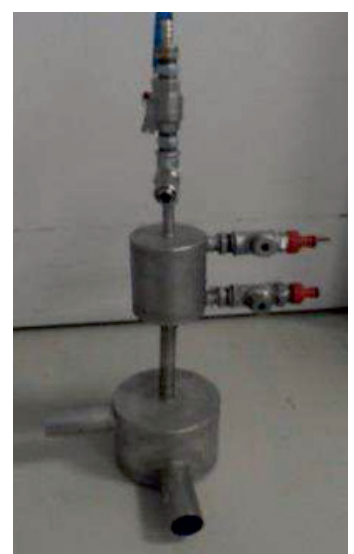

Figure 2. Experimental device for measuring the performance parameters heat-pipe.

The experimental device is completely made of stainless steel and consists of three parts. Bottom part of device is used to heat transport from the air to the evaporation section of the heat pipe, which is filled with working fluid to with a certain volume. The central part

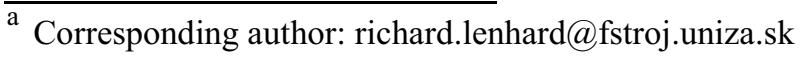


of the device is an adiabatic section of the heat pipe. The top part of the experimental device is used to heat transport from the condensation section to heat carrying substance, in this case to water. In the inlet and outlet of heat carrying substance is installed a surface hole for a resistance thermocouple. On top of the heat pipe is prepared a connection of a tensometric pressure gauge for recording pressure in the heat pipe. At the end of the heat pipe is installed a gas-tight ball valve with the possibility of repeated filling and vacuuming of the working fluid in the heat pipe. The experimental device is insulated with sufficient insulation in order to minimize heat loss.

\subsection{Measuring procedure for experimental device}

The experimental device is connected to measuring network according to figure 3. Evaporation section of heat pipe is heated by hot air (hot air gun) with adjustable heating temperature from $50{ }^{\circ} \mathrm{C}$ up to $650{ }^{\circ} \mathrm{C}$. Inlet and outlet air temperature are measured by the temperature sensors of the type Pt 100.

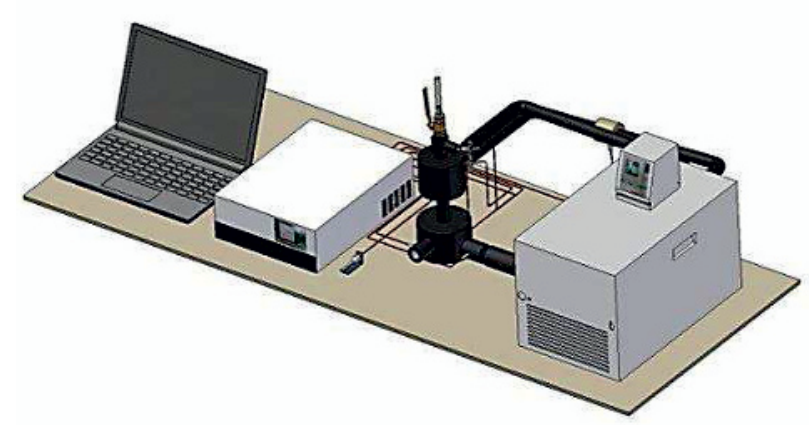

Figure 3. Engaging experimental equipment.

Condensation section of heat pipe is cooled by means water and flow cooling thermostat from company Julabo. The heat from the condensation section of heat pipe is taken away by water flow cooling, which temperature is maintained at $20^{\circ} \mathrm{C}, \quad 40^{\circ} \mathrm{C}$ and $60^{\circ} \mathrm{C}$ by means thermostat Julabo. Volume flow rate is measured at the cooling water inlet and the temperatures are recorded at its inlet and outlet. Heat transfer performance of the heat pipe from the evaporation to the condensation section is calculated on the basis of this way measured values.

Heated and cooled section of the experimental device is insulated with Armaflex insulation, due to heat loss to environment and measurement precision by calorimetric method. All measured values (inlet and outlet air temperature, inlet and outlet water temperature, ambient temperature, cooling water flow, pressure in the heat pipe) were recorded at 2-second intervals by software AMR-WinControl of measuring panel AHLBORN ALMEMO 5690 for computer.

\subsection{Evaluation of measurements on experimental device}

The measurement is carried out with the gravitational heat pipe, which is filled with distilled water used as the working fluid with filling volumes $10 \%, 20 \%$, and $30 \%$ of the heat pipe. Mean heat pipe performance [W] is determined from the measured values according to the calorimetric method:

$$
\bar{Q}=\dot{m} \cdot c \cdot \overline{\Delta t} .
$$

Table 1. Heat output at $10 \%, 20 \%, 30 \%$ filling.

\begin{tabular}{|c|c|c|c|c|}
\hline Filling & Temp. & $\mathbf{1 2 0}^{\circ} \mathbf{C}$ & $\mathbf{1 4 0}^{\circ} \mathbf{C}$ & $\mathbf{1 6 0}^{\circ} \mathbf{C}$ \\
\hline \multirow{3}{*}{$10 \%$} & $20^{\circ} \mathrm{C}$ & 42.16 & 53.47 & 61.25 \\
& $40^{\circ} \mathrm{C}$ & 31.92 & 43.04 & 51.63 \\
& $60^{\circ} \mathrm{C}$ & 16.21 & 26.32 & 34.97 \\
\hline \multirow{3}{*}{$20 \%$} & $20^{\circ} \mathrm{C}$ & 32.30 & 42.40 & 51.09 \\
& $40^{\circ} \mathrm{C}$ & 30.28 & 39.90 & 50.04 \\
& $60^{\circ} \mathrm{C}$ & 18.02 & 28.44 & 39.43 \\
\hline $30 \%$ & $20^{\circ} \mathrm{C}$ & 38.81 & 46.21 & 54.30 \\
& $40^{\circ} \mathrm{C}$ & 31.41 & 37.59 & 46.96 \\
& $60^{\circ} \mathrm{C}$ & 17.55 & 24.89 & 33.68 \\
\hline
\end{tabular}

\begin{tabular}{|c|c|c|c|c|c|}
\hline Filling & Temp. & $\mathbf{1 8 0}^{\circ} \mathbf{C}$ & $\mathbf{2 0 0}^{\circ} \mathbf{C}$ & $\mathbf{2 4 0}^{\circ} \mathbf{C}$ & $\mathbf{2 6 0}^{\circ} \mathbf{C}$ \\
\hline \multirow{3}{*}{$10 \%$} & $20{ }^{\circ} \mathrm{C}$ & 72.42 & 82.31 & 91.75 & 101.92 \\
& $40^{\circ} \mathrm{C}$ & 60.35 & 70.78 & 80.60 & 91.22 \\
& $60{ }^{\circ} \mathrm{C}$ & 38.03 & 48.93 & 60.69 & 69.16 \\
\hline \multirow{3}{*}{$20 \%$} & $20{ }^{\circ} \mathrm{C}$ & 61.25 & 72.14 & 83.00 & 94.90 \\
& $40^{\circ} \mathrm{C}$ & 60.50 & 69.90 & 80.00 & 92.00 \\
& $60^{\circ} \mathrm{C}$ & 46.95 & 58.10 & 68.71 & 71.36 \\
\hline \multirow{3}{*}{$30 \%$} & $20^{\circ} \mathrm{C}$ & 61.41 & 70.82 & 85.31 & 94.97 \\
& $40{ }^{\circ} \mathrm{C}$ & 49.72 & 59.48 & 67.95 & 76.78 \\
& $60{ }^{\circ} \mathrm{C}$ & 42.13 & 50.01 & 56.72 & 67.82 \\
\hline
\end{tabular}

For all types of heat pipe have been made the measurements for heating air temperatures from $120{ }^{\circ} \mathrm{C}$ up to $260{ }^{\circ} \mathrm{C}$ and always at different cooling water temperatures $20^{\circ} \mathrm{C}, 40{ }^{\circ} \mathrm{C}$ and $60^{\circ} \mathrm{C}$. Each measurement of heat performance for the heating air temperature lasts for 30 minutes. Heat outputs calculated from various measurements at different volume of heat carrier substance are shown in Table 1.

They can see from Table 1 that heat performance transferred by heat pipe at $10 \%$ volume filling of heat pipe is increased by $30 \%$. It is also seen that in case of the cooling water at the temperature $20{ }^{\circ} \mathrm{C}$ is transferred heat performance considerably higher while using all fillings. While is cooling water temperature set on $40^{\circ} \mathrm{C}$ and $60^{\circ} \mathrm{C}$, they can see from the results in Table 1 that transferred heat performances are different at lower temperatures but at higher temperatures on the heated side are gradually aligned.

\section{Numerical model heat-pipe}

Modeling of heat transfer in heat pipes is carried out to compare the measured results and results obtained using CFD methods, and also in order to visualize the behavior of the working fluid in the heat pipe.

The purpose of numerical simulation of heat-pipe execution was non-stationary heat-pipe simulation in 
ANSYS Fluent in which takes into account the evaporation and condensation of working fluid (water). It was created 2D and 3D model heat-pipe. Heat pipe consists of evaporating part, adiabatic part and condenser part. A model system consist of water, steam and air (non-condensing component). In order to speed up the calculation and correct adjustment of boundary conditions for the other models are first created a simplified 2D model, which was created in ANSYS Workbench programming environment. It is a cylinder of height of $400 \mathrm{~mm}$ and width $32 \mathrm{~mm}$ (figure 4).

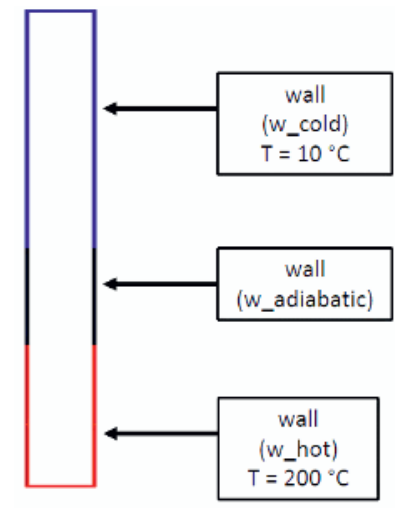

Figure 4. Boundary condition on heat-pipe.

\subsection{Preferences and boundary conditions}

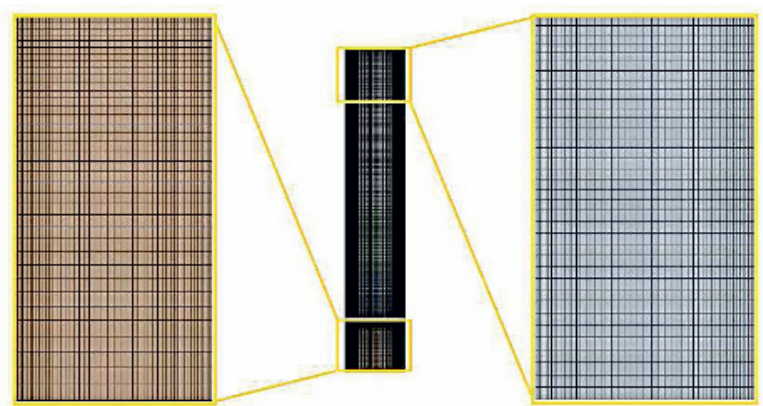

Figure 5. Detail computing mesh.

Table 2. Setting solver.

\begin{tabular}{|c|c|c|c|}
\hline Dimension & Precision & Convection & $\begin{array}{l}\text { Setting up the } \\
\text { model }\end{array}$ \\
\hline \multirow[t]{2}{*}{$\begin{array}{l}2 \mathrm{D} \\
\text { and } \\
3 \mathrm{D}\end{array}$} & double & non-stationary & $\begin{array}{c}\text { Evaporation- } \\
\text { condensation: } \\
\mathrm{T}_{\mathrm{sat}}=60^{\circ} \mathrm{C} \\
\beta_{1}=0.1 \\
\beta_{\mathrm{v}}=10\end{array}$ \\
\hline & & $\begin{array}{c}\text { incompressible, } \\
\text { laminar }\end{array}$ & $\begin{array}{c}\text { Multiphase } \\
\text { model: } \\
\text { mixture } \\
\text { The liquid } \\
\text { phase }=\text { water, } \\
\text { gas phase }=\text { id. } \\
\text { mixture of } \\
\text { steam + air }\end{array}$ \\
\hline
\end{tabular}

Flow in the laminar regime $(\operatorname{Re}>100)$. For a description of interfacial mass transport model was used Evaporation-Condensation [5].

$$
\begin{aligned}
& \text { If: } T_{l}>T_{\text {sat }} \text { then: } \dot{m}_{l \rightarrow v}=\beta_{l} \cdot \alpha_{l} \cdot \rho_{l} \frac{T_{l}-T_{s a t}}{T_{s a t}} \\
& \quad \text { otherwise } \dot{m}_{l \rightarrow v}=0 \mathrm{~kg} \cdot \mathrm{s}^{-1} . \\
& \text { If: } T_{v}>T_{\text {sat }} \text { then: } \dot{m}_{v \rightarrow l}=\beta_{v} \cdot \alpha_{v} \cdot \rho_{v} \frac{T_{v}-T_{s a t}}{T_{s a t}} \\
& \text { otherwise } \dot{m}_{v \rightarrow l}=0 \mathrm{~kg} \cdot \mathrm{s}^{-1} .
\end{aligned}
$$

\subsection{The results of CFD simulations of 2D model heat-pipe}

Using ANSYS FLUENT software was transferred nonstationary simulation of the heat-pipe in the time interval 0 to $600 \mathrm{~s}$ for $2 \mathrm{D}$ and for 3D it was $60 \mathrm{~s}$. For a description of interfacial mass transport model was used Evaporation-Condensation. The model was able to describe the mechanism of boiling and condensation.

CFD simulation of heat-pipe was designed for a system containing $13 \%$ vol. and $20 \%$ vol. Liquid water remaining $\%$ contain a mixture of air and water. To start the simulation were first counted from stationary temperature field simulation (solution of the equation of energy).

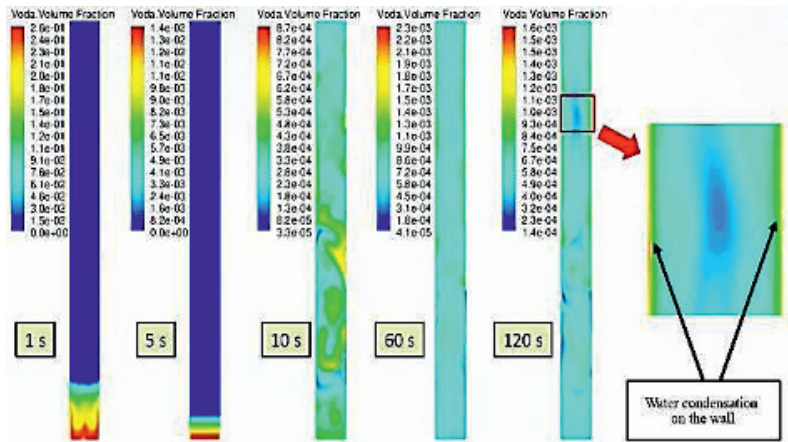

Figure 6. Contour of water volume fraction.
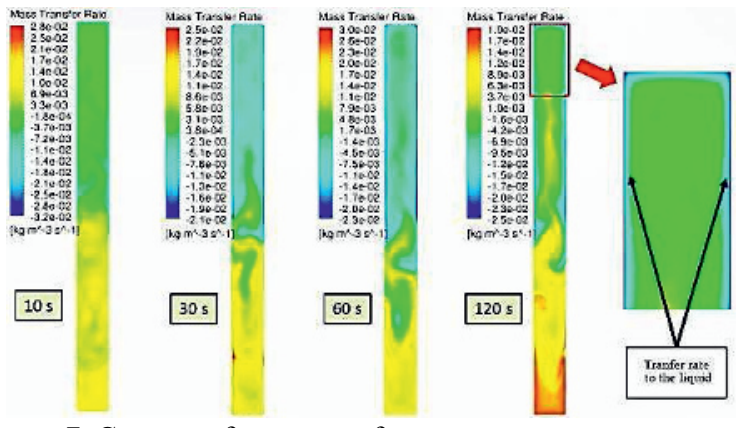

Figure 7. Contour of mass transfer rate.
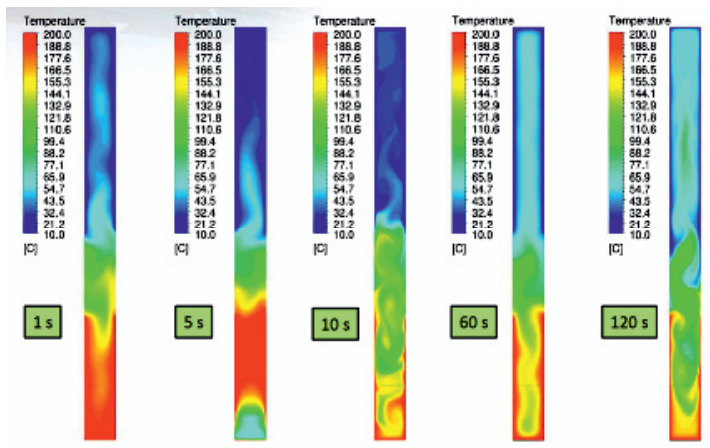

Figure 8. Contour of temperature 


\section{Conclusion}

Comparing the results from $2 \mathrm{D}$ and $3 \mathrm{D}$ simulation processes in heat-pipe with the measured values of performance, it was found that the $2 \mathrm{D}$ models were the results too high inaccuracy (Table 3 ) and when the model was able to describe the mechanism of boiling and condensation. The 2D model started if there is a much faster process than it was in $3 \mathrm{D}$ simulations. The results of performance with $3 \mathrm{D}$ simulation are close to the measured values. Therefore, it is possible to say that the CFD modeling processes in heat pipes 2D model is not sufficient and it is necessary to solve such a role 3D. Thus developed CFD models can also serve to simulate various heat pipe designs and to be used for other modeling boiling and condensation heat transfer with various substances and amounts fillings. The CFD simulation of heat pipe was also found that the mere simulation is very time consuming and performance computer equipment. This argument can be seen in the 3D simulation heat-pipe, which is calculated one minute. This calculation took about 10 days for high-performance clusters.

Table 3. Comparison of the results with simulation and measurement.

\begin{tabular}{|c|c|c|}
\hline \multicolumn{3}{|c|}{ Time } \\
\hline Model & $60 \mathrm{~s}$ & $600 \mathrm{~s}$ \\
\hline $2 \mathrm{D}$ & $382.8 \mathrm{~W}$ & $341.7 \mathrm{~W}$ \\
\hline $3 \mathrm{D}$ & $61.5 \mathrm{~W}$ & \\
\hline Measuring & $79.9 \mathrm{~W}$ & \\
\hline
\end{tabular}

From the analysis of the initial measurements, the proposed experimental device was tested and proved that by proposed calorimetric method is relatively easy to measure the performance characteristics of heat pipes, which are filled with various kinds of working substances and their volumes, heating temperatures in the evaporation section of heat pipe and the cooling temperature in the condensation section. On the proposed experimental device, they will make other series of measurements with various settings of volume and sort of the working filling while maintaining the same conditions during heating and cooling of heat pipe. These results then provide the database of comparative data for carrying out measurements on a real prototype of domestic hot water storage tank, which uses the heat from the hot flue gases by the heat pipe. The results help to create more mathematical models that could be used for other proposals of heat pipes.

\section{Acknowledgments}

This contribution was created within the frame of project VEGA č. 1/1290/12.
This contribution is the result of the project implementation: Slovak Infrastructure for High Performance Computing, ITMS code 26230120002, supported by the Research \& Development Operational Program funded by the ERDF.

\section{References}

1. R. Lenhard, M. Malcho, Mathematical and Computer Modelling, 57, 111 (2013)

2. P. Nemec, A. Čaja, M. Malcho, Mathematical and Computer Modelling, 57, 126 (2013)

3. R. Lenhard, M. Jakubský, M. Malcho, J. Jandačka, Communications: scientific letters of the University of Žilina, 14, 10 (2012)

4. M. Kasanický, S. Gavlas, M. Vantúch, M. Malcho, Experimental fluid mechanics, 332 (2012)

5. W. H. Lee, A pressure iteration scheme for two phase modeling, Los Alamos Scientific laboratory. Los Alamos, New Mexico, (1979)

6. S. C. K. De Schepper, G. J. Heynderickx, G. B. Marin, Chemical Engineering Journal, 138 (2008)

7. K. Kaduchová, R. Lenhard, J. Jandačka, The application of experimental and numerical methods in fluid mechanics and energy, 119 (2012)

8. P. Novotný, T. Vít, P. Dančová, 17th International Conference on Engineering Mechanics, Engineering mechanics 2011, 439 (2011), (WOS:000313492700103)

9. R. Lenhard, Power control and optimization, (2010) 